\title{
A HORA DA ESCRITA: \\ CLARICE LISPECTOR, LINGUAGEM E METAFICÇÃO
}

\author{
Raimunda Maria Santos \\ Joelma de Araújo Silva Resende ${ }^{* *}$ \\ Sebastião Alves Teixeira Lopes**
}

RESUMO: O objetivo do presente artigo é examinar a narrativa $A$ bora da estrela, observando o fazer literário de Clarice Lispector. A autora transforma a linguagem em elemento estético, apostando no intimismo e na reflexão constante sobre os limites e falibilidade da palavra, sobre a impossibilidade de dizer. Para ressaltar a força estética da linguagem de Clarice, recorre-se, dentre outros, aos conceitos de (auto)ficção e metaficção. Trata-se de uma prática narratológica que transforma a própria existência e labor em matéria literária, demonstrando a angústia de viver e escrever, ao passo que, metaficcionalmente, coloca a linguagem em escrutinação. Em forma de conclusão, apontamos como a autora continua a desafiar e seduzir uma legião de leitores por, de forma metaficcional narcisista, apostar na complexidade da linguagem.

PALAVRAS-CHAVE: A hora da estrela. Clarice Lispector. Linguagem. Metaficção.

\section{Considerações iniciais}

Existir e escrever enleiam-se em Clarice Lispector. A palavra é-lhe frágil e doloroso instrumento de subsistência. Através das letras, expressa-se; com elas age e resiste; delas provém-se; nelas encontra-se, é e perdura. Escrevendo, elabora sua intimidade, apresenta seus tormentos e angústias, inscreve-se no mundo e, principalmente, fala da aflição face à página em branco. Nesse processo metanarrativo, ou seja, nessa forma textual de autorreflexão - a metaficção conforme Linda Hutcheon (1984), Clarice transforma a linguagem em uma estética do cotidiano, a seduzir leitores pela enunciação da dor de ser e de escrever.

Existir $^{1}$, no sentido etimológico do termo (do latim - existere), sugere nascer ou aparecer ou ainda, ir para fora, sair de si, levantar-se, tornar-se visível. Para usar o vocabulário de A hora da estrela, implica no direito de gritar. Clarice, contudo, escreve a partir de sua intimidade, revelando um mundo interior, a partir da realidade que vivencia. Conta com o uso estético da linguagem para realizar crítica social. Essa ambivalência entre o íntimo e o

\footnotetext{
* Professora da Universidade Federal do Piauí (Ufpi). Doutoranda em estudos de Literatura pela Universidade Federal do Rio Grande do Sul (UFRGS). Mestre em Letras pela Ufpi.

** Mestre em Letras pela Universidade Federal do Piauí, (Ufpi). Professora do Instituto Federal do Piauí (Ifpi).

*** Doutorado em Letras (Língua Inglesa Liter. Inglesa e Norte-Americana) pela Universidade de São Paulo, (Usp). Professor Associado I da Fundação Universidade Federal do Piauí (Fupfi).

${ }^{1}$ Conforme o Dicionário Etimológico: etimologia e origem das palavras. Disponível em: https://www.dicionarioetimologico.com.br/existir/. Acesso em: 21/08/2020.
} 
externo, caracteriza a escrita de Clarice, marcada por uma palavra-vivência ${ }^{2}$ que, a partir daquilo que lhe é muito íntimo, procura compreender o mundo.

Escrever é uma forma de apresentar-se para o Outro. Pressupõe um manifestar-se a... Da mesma forma, publicar é desparzir-se. Subentende ir além de si. A linguagem permite a ponte entre o Eu e o Outro. Esse elo, contudo, não é mimético, mas baço. A linguagem não é capaz de apreender com exatidão e totalidade o real. No bojo da própria escrita, Clarice alerta para a falibilidade da linguagem, em uma estratégia metaficcional que explicita o processo criativo e deixa clara a ficcionalidade da diegese.

O objetivo do presente artigo é examinar $A$ bora da estrela, observando o fazer literário de Clarice, que transforma a linguagem em elemento estético, apostando no intimismo da autora e na reflexão constante sobre os limites da palavra, sobre a impossibilidade de dizer. Trata-se de uma prática narratológica que transforma a própria existência e labor em matéria literária, demonstrando a angústia de viver e escrever, ao passo que, metaficcionalmente, coloca a linguagem em escrutinação.

\section{Palavra-vivência: a (auto)ficcionalidade de Clarice}

Nascida na Ucrânia, Clarice veio para o Brasil, ainda pequena e viveu a infância no Nordeste brasileiro (Maceió e Recife) e Sudeste (no Rio de Janeiro) e, quando adulta, residiu por 16 anos no exterior (Itália, Suíça, Inglaterra e Estados Unidos), acompanhando o marido diplomata. Escreveu uma peça Pobre menina rica aos 9 anos e não parou mais; após publicar contos, aos 23 anos intensificou ainda mais suas experiências como escritora, quando lança a obra Perto do coração selvagem. Segundo esclarece Nolasco (2004) sobre a trajetória literária de Clarice,

\footnotetext{
A autora não só fez de sua vida matéria para a ficção, como se tornou, de forma singularíssima, seu próprio tema ficcional. Muitos de seus textos, por exemplo, vão ter como pano a memória da infância vivida, e de suas reminiscências para a construção de sua fiç̧ão. Nessa visita ao passado, tentativa vã de reconstituir fatos que ficaram perdidos na sua história pessoal, ficcionaliza extrapolando, em muito, os limites do acontecido. (NOLASCO, 2004, p.78-79)
}

Essa (auto)ficção sutil e complexa atribui à narrativa de Clarice um tom confidencial, no qual sobressai a linguagem intimista da autora, a criar uma grande cumplicidade entre autora e leitores. A prosa de Clarice revela o que há de íntimo da escritora e de seus personagens, considerando que as emoções e sentimentos refletem-se na linguagem da autora. Nesse sentido caracteriza-se um estilo intimista. A crítica literária de cunho biográfico

\footnotetext{
2 Barbosa e Moraes (2007-2008) usam o termo 'palavra-experiência'.
} 
dedicada à Clarice rastreia justamente a presença da autora na obra literária, considerando dentre outros aspectos, a extrapolação da autora, que se difunde para o texto literário.

\footnotetext{
Percebemos (...) que Lispector procura buscar, em sua memória, em seu passado, dentro de suas relações mais íntimas, as informações necessárias para construir a narrativa da pobre moça, que, por hora, tentou esconder durante sua produção, mas que, em $A$ hora da estrela emergiu como uma válvula de escape. (FIGUEIREDO, 2013, p. 43-GRIFO NOSSO)
}

Ainda que tenha tentado esconder (omitir) suas origens em seus escritos, conforme deixa claro Figueiredo no trecho grifado, Clarice parte de seu próprio íntimo, suas memórias da infância no Nordeste brasileiro, a mudança para o Rio de Janeiro, suas angústias pessoais, para construir Macabéa, uma personagem de cunho social, fazendo uso de uma palavra-vivência capaz de ser ao mesmo tempo interior e exterior, apropriada tanto para falar de si, como para criticar a mediocridade do mundo.

Clarice enquanto escritora contribui com a literatura brasileira, introduzindo a literatura intimista no Brasil. Em um processo de construção de seu próprio estilo linguístico, sem se afastar do intimismo e epifânico, utiliza mecanismos literários explícitos de metalinguagem. Assim, dá vazão ao que Linda Hutcheon (1984) chama de 'mimese do processo', ou seja, textos literários que trazem manifestos em seu bojo. No caso de $A$ hora da estrela, os manifestos tratam-se dos percalços do processo de construção textual. Tem-se, portanto, uma literatura intimista por traduzir emoções e sentimentos, através de um processo de potencial autorreflexão - a metaficção.

Do início de sua vida literária, considerando suas constantes criações psicológicas descritivas de caráter complexo e de riqueza poética, a linguagem peculiar da autora vai desenhando-se para uma prática desconstrucionista em que se percebe o empenho de Clarice em adotar estratégias metaficcionais, a exemplo da criação da personagem-narrador-autor de $A$ hora da estrela, através do qual pode escrever sobre a escrita. "Escrevo sobre o mínimo parco enfeitando-o com púrpura, joias e esplendor. É assim que se escreve? Não, não é acumulando e sim desnudando. Mas tenho medo da nudez, pois ela é a palavra final. (LISPECTOR, 1998, p. 82). Percebe-se que Clarice compõe um personagem autocrítico. Ao fazer uma autorreflexão sobre o processo de escrita, o personagem-narrador-autor, de e por Clarice faz um julgamento de seu próprio processo e estilo de escrever.

No Brasil, ambientada no clima de autoritarismo do período da Ditadura Militar iniciado em 1964, Clarice lança em 1977 A bora da estrela, narrativa de temática social, aproximando-se da realidade por uma abordagem psicológica. Nesse sentido, a história narrada inclui experiências desse contexto e aproxima-se da própria história da autora. Segundo 
Bakthin (1998, p. 69), “O objeto estético é uma criação que inclui em si o criador”. A forma como usa a linguagem é um dos tópicos que mais chama a atenção de pesquisadores da obra de Clarice. Particularmente nesse tema, revela-se a complexidade da autora, alcançando o ponto máximo em $A$ bora da estrela, através da complexidade da personagem-narrador-autor Rodrigo S. M. ${ }^{3}$ e da simplicidade da datilógrafa Macabéa, todos, inclusive Clarice, profissionais da escrita.

Barbosa e Moraes defendem que a faceta estética da linguagem de Clarice reside na desautomatização da vida (2007-2008). Para elas, “a autora insere-se na própria escrita, fazendo, através da linguagem, questionamentos profundos do ser e da palavra, que ultrapassam o cotidiano, o superficial da língua e de seus significados" (BARBOSA e MORAES, 2007-2008, p. 81). As autoras ressaltam que a forma como Clarice se deixa fluir na própria narrativa rompe com o esperado, alçando a linguagem a patamares estéticos inalcançáveis pelas gastas e perfunctórias palavras do dia-a-dia. "É essa constante reinvenção da linguagem poética e da vida que torna a escritura de Clarice um texto revitalizador da língua portuguesa e da literatura brasileira", apregoam Barbosa e Moraes (2007-2008, p. 82).

Esse processo de tecer-se narrativa, fazendo uso de uma palavra-vivência desautomatizada com a qual se constrói enquanto sujeito, autora e trama, atribui especial valor estético para a linguagem de $A$ hora da estrela, fazendo da novela uma (auto)ficção repleta de estratégias metaficcionais e difícil de catalogar.

\title{
Linguagem e autorreflexividade em $\boldsymbol{A}$ hora da estrela
}

Apesar de não se tratar de um fenômeno recente, a metaficção torna-se uma forte tendência entre os romances pós-modernos a partir da década de 1960. Segundo Borges, a metaficção:

\begin{abstract}
é vista como a intercessão entre produtor, texto e receptor, constituindo-se dos contextos social, ideológico, histórico e estético. Consequentemente, ela ultrapassa a autorreflexividade e situa o discurso em um sentido mais amplo, uma vez que é fundamentalmente irônica e crítica em relação ao passado e presente. (BORGES, 2009, p. 14)
\end{abstract}

A metaficção reflete uma tentativa de encontrar um modo estético de abordar as experiências do ser humano na pós-modernidade. Essas experiências têm-se mostrado desordenadas e a arte, de uma forma consoladora, tende a estabelecer ordem em meio ao caos

\footnotetext{
${ }^{3}$ De acordo com Paulo Verneck (2017), a personagem-narrador-autor Rodrigo S. M. foi inspirado pelo Dr. Sérgio Matta (S. M.), auxiliar cirúrgico que acolheu Clarice durante um procedimento cirúrgico na clínica do Dr. Ivo Pitanguy, no Rio de Janeiro. Matta chega a dizer, segundo Verneck, que Clarice o adotou talvez porque o considerou, de certa forma, um 'macabeu'.
} 
pós-moderno. Já para Hutcheon, trata-se de uma estratégia textual que proporciona ao leitor a consciência da produção e recepção do texto como produto cultural. Nesse caso, o autor produz um artefato (o texto) provocador de mudanças sociais através dos seus leitores. Uma dessas mudanças é a possibilidade de aclarar a questão da verdade ficcional.

\begin{abstract}
O que sempre foi uma verdade da ficção, embora raramente consciente, é trazido à tona em textos modernos: a criação de mundos fictícios e o funcionamento construtivo, criativo da linguagem em si, são agora autoconscientes, compartilhados por autor e leitor. $O$ último não é mais solicitado apenas para reconhecer que os objetos de ficção são "como a vida", ele é convidado a participar na criação de mundos e de significado, através da linguagem. (HUTCHEON, 1984, p. 30).
\end{abstract}

Em relação à linguagem do romance ficcional, Hutcheon afirma que esta é sempre representacional. Na metaficção, esse fato é explícito, pois enquanto o leitor lê, vive em um mundo que o força a reconhecê-lo como ficção. Essa estratégia implica na participação do leitor na recriação do texto de maneira intelectual, imaginária e efetiva. De acordo com $\mathrm{Hu}$ tcheon, a narrativa metaficcional leva o leitor a reconhecer a responsabilidade pela leitura que realiza, pelo heterocosmo dinâmico - sistema ordenado e harmonioso - que está sendo criado através dos referentes ficcionais da linguagem literária.

De acordo com Reichmann (2006), através do processo de espelhamento, o metaficcionista pode querer perturbar seu leitor. A leitura pode deixar de ser uma experiência agradável e tornar-se um ato desafiante e ameaçador. A leitura torna-se um processo paralelo ao da escrita; em consequência disso, o leitor tem uma participação maior no processo.

A natureza do texto metaficcional acrescenta a dimensão da liberdade ao processo imaginativo e linguístico do leitor. Essa liberdade atinge leitor e autor, mas o crítico também a desfruta ao ficar livre de uma metodologia única, já que a metaficção carrega em si uma própria estrutura crítica de referência, que é parte de seu tema e de sua forma.

De acordo com Hutcheon (1984 apud NAVAS, 2007), a metaficção é uma espécie de ficção que inclui em si um comentário sobre sua própria narrativa ou identidade linguística. A metaficção tem como focos principais as estruturas linguísticas e narrativas, além do papel do leitor. Trata-se do "processo do narrar tornado visível” (1984 apud NAVAS, 2007, p. 59). $\mathrm{Na}$ narrativa metaficcional, o autor chama a atenção do leitor para a escrita como um evento dentro do próprio romance, exibindo seus sistemas - o ficcional e o linguístico - ao leitor.

Em $A$ bora da estrela, o texto encontra-se carregado de reflexões da personagem-narrador-autor, demandando um leitor participativo. Pela natureza do tipo de orientação metaficcional, a novela apresenta uma carga ilusória, dando a impressão de que o está sendo escrito ali, no momento de sua leitura. Ao final da trama, a personagem-narrador-autor parece não estar sozinho ou no passado do leitor. 


\begin{abstract}
Acho com alegria que ainda não chegou a hora de estrela de cinema de Macabéa morrer. Pelo menos ainda não consigo adivinhar se lhe acontece o homem louro e estrangeiro. Rezem por ela e que todos interrompam o que estão fazendo para soprar-lhe vida, pois Macabéa está por enquanto solta no acaso como a porta balançando ao vento no infinito. (LISPECTOR, 1998, p. 85)
\end{abstract}

Como um reflexo de sua vida, agora ficcionalizada, Clarice escreve a história da nordestina que levava uma vida de datilógrafa. Faz isso através da composição de uma personagem-narrador-autor que escreve sobre o processo de escritura dessa história, contando com a presença participativa do leitor. É difícil de imaginar situação mais metaficcional do que essa.

Antes mesmo de narrar a história de Macabéa, Rodrigo S. M. apresenta suas reflexões sobre a escrita, fazendo questionamentos sobre o processo narratológico.

Enquanto eu tiver perguntas e não houver resposta continuarei a escrever. Como começar pelo início, se as coisas acontecem antes de acontecer? Se antes da prépré-história já havia os monstros apocalípticos? Se esta história não existe passará a existir. Pensar é um ato. Sentir é um fato. (LISPECTOR, 1998, p. 11)

As reflexões e questionamentos apresentados por Rodrigo S. M. exigem a participação ativa do leitor, que no momento da leitura reflete também sobre o processo de escrita, ecoando o que ressalta Hutcheon, ao defender que na narrativa metaficcional o leitor é um participante ativo da construção textual. Vejamos abaixo:

Como eu irei dizer agora, esta história será o resultado de uma visão gradual - há dois anos e meio venho aos poucos descobrindo os porquês. É visão da iminência de. De quê? Quem sabe se mais tarde saberei. Como que estou escrevendo na hora mesma em que sou lido. Só não inicio pelo fim que justificaria o começo como a morte parece dizer sobre a vida - porque preciso registrar os fatos antecedentes. (LISPECTOR, 1998, p. 12)

Rodrigo S. M. coloca-se como personagem, segundo ele "um dos mais importantes deles, é claro" (LISPECTOR, 1998, p. 13). Antecipa que sua história é um relato convencional, pois não se considera moderno ou adepto de modismos. Sua narrativa, portanto, apresentará uma estrutura tradicional, com início, meio e fim. Não se trata, contudo, de um final qualquer, como ele próprio grifa no trecho seguinte: "Relato antigo, este, pois não quero ser modernoso e inventar modismos à guisa de originalidade. Assim é que experimentarei contra os meus hábitos uma história com começo, meio e "granfinale" seguido de silêncio e de chuva caindo”. (LISPECTOR, 1998, p. 13)

Rodrigo S. M. introduz aos poucos a história de Macabéa. Parece não estar preparado para narrar a história triste dessa nordestina que ele descreve como uma pessoa que "ninguém a quer, ela é virgem e inócua, não faz falta a ninguém" (LISPECTOR, 1998, p.14). Nesse instante, compara-se a Macabéa, afirmando que não faria falta, sendo que o que escreve 
qualquer outro escreveria. Adiante, mais uma vez hesita antes de narrar a história da nordestina: "Estou esquentando o corpo para iniciar, esfregando as mãos uma na outra para ter coragem. Agora me lembrei de que houve um tempo em que para me esquentar o espírito eu rezava: o movimento é espírito" (LISPECTOR, 1998, p. 14).

$A$ bora da estrela apresenta-se em forma de relato metaficcional, por demonstrar as reflexões de Rodrigo S. M. sobre o processo de criação da história de Macabéa assim como o de sua própria história. De acordo com Franco Júnior (2008, p. 60), na novela "há um viés metalinguístico de função irônica que acompanha o fazer e a reflexão sobre o fazer literário". Para o citado teórico, Rodrigo S. M. é um sádico na construção de Macabéa; o narrador utiliza esse recurso para conter o apelo sentimental que se afirma pelo avesso. Se Macabéa é o cúmulo da miséria, Rodrigo S. M. é o cúmulo da crueldade.

O anseio pelo insight acomete qualquer escritor, porém Rodrigo S. M. não deixa de destilar sua ironia. Vê-se que a comparação com Macabéa pode ter procedência, ou não, a depender do balanço do texto feito pelo leitor, ao avaliar o perfil da personagem-narradorautor, que declara:

É claro que, como todo escritor, tenho a tentação de usar termos suculentos: conheço adjetivos esplendorosos, carnudos substantivos e verbos tão esguios que atravessam agudos o ar em vias de ação, já que palavra é ação, concordai? Mas não vou enfeitar a palavra, pois se eu tocar no pão da moça esse pão se tornará em ouro - e a jovem poderia mordê-lo, morrendo de fome. Tenho então que falar simples para captar a sua delicada e vaga existência. (LISPECTOR, 1998, p. 15 GRIFO NOSSO)

Rodrigo S. M. afirma que escreverá de modo simples, porque o material que dispõe para sua narração também é muito simples, as informações são parcas. Poderia, segundo ele, usar "adjetivos esplendorosos" ou "carnudos substantivos", mas prefere não enfeitar e contar a história de forma bem simples em concordância com a vida de Macabéa. Tais preocupações demonstram o nível de autorreflexão da personagem-narrador-autor, provocando uma participação avaliativa que se estende à própria escritora, assim como ao leitor, se considerarmos a interlocução sugerida, por exemplo, pelo uso do verbo 'concordai', grifado no trecho acima.

Rodrigo S. M. continua a retardar a narrativa, como se fugisse dela: "Sei que estou adiando a história e que brinco de bola sem bola. O fato é um ato? Juro que este livro é feito sem palavras. É uma fotografia muda. Este livro é um silêncio. Este livro é uma pergunta" (LISPECTOR, 1998, p. 16-17). Adiante, reconhece seu medo. Antes de Macabéa, segundo ele, era um homem não muito feliz, apesar do insucesso na literatura. Porém, transgredir os limites o fascinou e escrever sobre a realidade era algo que já não controlava, admitindo a necessidade de "falar dessa nordestina” (LISPECTOR, 1998, p. 17), para que não se sufoque. 
Rodrigo S. M. questiona-se sobre o motivo pelo qual escreve, respondendo a si mesmo que a escrita o domina, é algo incontrolável: "Porque escrevo? Antes de tudo porque captei o espírito da língua e assim às vezes a forma é que faz conteúdo. Escrevo portanto não por causa da nordestina mas por motivo grave de "força maior" como se diz nos requerimentos oficiais, por "força de lei” (LISPECTOR, 1998, p. 18).

O escritor também afirma que o processo de escrita é muito difícil, ele precisa pôr-se no nível da personagem para descrevê-la. No caso da narrativa de Macabéa, revela que precisa não fazer a barba, não dormir, andar em farrapos: "Não, não é fácil escrever. É duro como quebrar rochas. Mas voam faíscas e lascas como aços espelhados. (...) O que me proponho a contar parece fácil e à mão de todos. Mas a sua elaboração é muito difícil” (LISPECTOR, 1998, p. 19). Uma vez mais, Rodrigo S. M. tenta justificar o porquê de escrever:

Escrevo por não ter nada a fazer no mundo: sobrei e não há lugar para mim na terra dos homens. Escrevo porque sou um desesperado e estou cansado, não suporto mais a rotina de me ser e se não fosse sempre a novidade que é escrever, eu morreria simbolicamente todos os dias. (LISPECTOR, 1998, p. 21)

Durante a narrativa, Rodrigo S. M. demonstra uma atitude depressiva, cansado do texto que escreve. Parece sentir-se tão medíocre quanto Macabéa:

Estou absolutamente cansado de literatura; só a mudez me faz companhia. Se ainda escrevo é porque nada mais tenho a fazer no mundo enquanto espero a morte. A procura da palavra no escuro. O pequeno sucesso me invade e me põe no olho da rua. Eu queria chafurdar no lodo, minha necessidade de baixeza eu mal controlo, a necessidade da orgia e do pior gozo absoluto. O pecado me atrai, o que é proibido me fascina. Quero ser porco e galinha e depois matá-los e beberlhes o sangue. Penso no sexo de Macabéa, miúdo mas inesperadamente coberto de grossos e abundantes pêlos negros - seu sexo era a única marca veemente de sua existência. Ela nada pedia mas seu sexo exigia, como um nascido girassol num túmulo. Quanto a mim, estou cansado. Talvez da companhia de Macabéa, Glória, Olímpico. O médico me enjoou com sua cerveja. Tenho que interromper esta história por uns três dias. (LISPECTOR, 1998, p. 70).

Há uma confusão envolvendo a personagem-narrador-autor, que se vê na escrita (na história de Macabéa) e que já não quer mais escrever história simples de começo, meio e fim. Para Rodrigo S. M., a escrita pode ser, ao mesmo tempo, fuga, porque serve de alheamento à vida desinteressante que leva, ou lugar de acolhimento, porque se torna o lugar possível de revelar o que lhe atrai e o que repudia. Esse engendramento da linguagem metaficcional mostra o verso e o anverso da proposta de escrita clariciana, sobretudo no que diz respeito ao explícito caráter autorreflexivo da narrativa de $A$ bora da estrela.

Diante o exposto e em concordância com Ferro \& Pôrto, o narrador Rodrigo S. M. assume um embate com a linguagem e enfatiza dois aspectos importantes na construção do texto metaficcional: "o primeiro refere-se ao aspecto linguístico e à estrutura narrativa e o 
segundo, ao papel do leitor" (2009, p. 3). O processo metalinguístico em que a escrita de Clarice dá conta da criação de uma personagem-narrador-autor, que por sua vez cria, em parceria com o leitor, a história da pobre nordestina.

A hora da estrela caracteriza-se como uma narrativa metaficcional pelas explicitações das dificuldades que Rodrigo S. M. enfrenta para produzir seu texto. A personagem-narradorautor não tem o hábito de construir narrativas lineares, não apresenta descrições totalizantes de suas personagens e, por isso, o leitor deve participar ativamente da construção da história.

Ao mesmo tempo em que narra a história de Macabéa, Rodrigo S. M. revela sua própria história. Compara-se à personagem, reflete sobre seu "ser", questiona seu papel como escritor. Além de questionamentos acerca do fazer literário, indagações também sobre o próprio Rodrigo S. M., sobre quem ele é.

\footnotetext{
Dessa maneira, encontramos, nesta obra de Clarice, uma relação conflituosa, porque pungente, entre linguagem e existência, entre o "ser" e a impossibilidade e/ou fracasso do "dizer". A autora, não sem alguma reticência, parece desacreditar que a palavra consiga engendrar a totalidade de sentido das coisas, o que, por sua vez, implica pensar numa não tradução do ser, no seu desajuste diante do real. (FERRO; PÔRTO, 2009, p. 6).
}

Para Ferro \& Pôrto (2009), Rodrigo S. M. possui uma relação conflitante com a linguagem, mas apesar disso promove reflexões sobre seu desenvolvimento interior, pelo fato de ser sujeito do próprio discurso. Já Macabéa, uma semianalfabeta que lida com a palavra alheia para sobreviver, não se beneficia do contato com a palavra, apenas reproduzindo o discurso dos outros.

Ao perceber que Clarice pode "desacreditar que a palavra consiga engendrar a totalidade de sentido das coisas", Ferro e Pôrto (2009) convocam-nos a refletir sobre a relação entre linguagem e identidade do sujeito e, nesse caso, não se pode conceber que Rodrigo S. M. e Macabéa sejam o que são pela palavra que proferem. No máximo pode a palavra ser elemento de identificação, mas não de identidade. Para Clarice, a palavra torna-se matéria prima para arte e, como já mencionado anteriormente, a autora revela um marcante diferencial com relação ao uso criativo da linguagem em sua obra e, sobretudo, revela consciência sobre a complexidade discursiva e as possibilidades de usos da palavra que envolve o processo de produção literária.

\section{Considerações finais}

Em $A$ hora da estrela, Clarice lança mão do modelar artifício metaficcional de construir uma personagem que é também autor, encontrando-se em processo de escrita de uma novela. Assim, a descrição do processo narratológico em si é colocada no centro da narrativa, 
fornecendo a oportunidade para a autora, através da personagem-narrador-autor, colocar no texto reflexões sobre o labor da escrita. Criam-se, assim, histórias dentro de histórias, narrativas em abismos que se fundem e se complementam.

Essa estratégia metaficcional concede especial atenção à linguagem, percebida como instrumento precário de comunicação entre os sujeitos. Dessa forma, Clarice apresenta todo o seu apreço pelas palavras, ao passo que denuncia seus limites. Aponta para a opacidade da linguagem, para a incapacidade de as palavras fazerem frente às complexidades da realidade e dos sentimentos. Ressalta a falibilidade da linguagem, único instrumento que possui para existir, para ir de encontro ao Outro, para apreender e julgar o mundo. Esse uso desautomatizado e autorreflexivo da linguagem concede a $A$ bora da estrela status de grande narrativa literária, capaz de seduzir legiões de leitores.

Tanto em Rodrigo S. M. quanto em Macabéa a linguagem apresenta-se como objeto de conflito. Para a personagem-narrador-autor, gera reflexões sobre o fazer literário, com suas angústias e hesitações. Para Macabéa, representa seu fracasso, sua incapacidade de usar as palavras, de gritar. Diante desse emaranhado de tramas e conflitos, o leitor é convidado a participar da tessitura da narrativa, a tornar-se coautor da urdidura textual, artifício metaficcional que rompe com a quarta parede, colocando o leitor também na cena que se desenrola.

De forma desautomatizada e autorreflexiva, Clarice faz da linguagem instrumento estético. Dilui-se em trama, criando assim uma complexa e sutil forma de (auto)ficção. Através de artifícios metaficcionais, desenvolve narrativas em distintos planos, através dos quais pode narrar e refletir sobre a narração, assim como interpelar diretamente o leitor, convidando-o a participar da construção textual. Ao apontar para a falibilidade da linguagem, afirma o indizível, o indecifrável. Clarice continua a nos desafiar e a nos seduzir.

THE TIME OF WRITING: CLARICE LISPECTOR, LANGUAGE AND METAFICTION

\begin{abstract}
The purpose of this article is to examine the narrative $A$ bora da estrela, observing the literary work of Clarice Lispector. The author transforms language into an aesthetic element, betting on intimacy and constant reflection on the limits and fallibility of the word, on the impossibility of saying. To highlight the aesthetic strength of Clarice's language, we use, among others, the concepts of (auto) fiction and metfiction. It is a narratological practice that transforms life and work into literary matters, demonstrating the anguish of living and writing, while, metaphorically, it puts language under scrutiny. In conclusion, we point out how the author continues to challenge and seduce a legion of readers by, in a narcissistic metafictional way, betting on the complexity of language.
\end{abstract}

KEYWORDS: $A$ hora da estrela. Clarice Lispector. Language. Metfiction.

\title{
REFERÊNCIAS
}

BAKHTIN, M. Questões de literatura e estética: a teoria do romance. 4. ed. São Paulo: Unesp, 1998. 
BARBOSA, V. M. C.; MORAES, V. L. A de. A linguagem de Clarice Lispector como desantomatização da vida. Revista de Letras, Vol. 1/2, nº 29, p. 81-84, (2007-2008).

BORGES, P. E. A metaficção historiográfica na literatura goiana: dois autores, duas obras. 2009. 96 f. Dissertação (mestrado) Departamento de Letras, Pontifícia Universidade Católica de Goiás, Goiânia, 2009.

FERRO, L. C. S; PÔRTO, L. V. A escrita de si ou uma análise metaficcional de $A$ hora da estrela. Letrônica, Porto Alegre, v. 2, nº 1, p. 330-340, jul. 2009.

FIGUEIREDO, Carlos Vinícius da Silva. A hora da estrela: uma biografia (auto)ficcional de Clarice Lispector. Macabéa. Revista Eletrônica do Netlli, Crato, v. 2, n. 1, p. 39-49, jun. 2013.

FRANCO JÚNIOR, A. Romance engajado, folhetim/melodrama e metaficção: $A$ hora da estrela. Revista de Letras, Universidade Federal do Ceará, vol. 1/2, no 29, p. 59-66, jan/dez. 2008.

HUTCHEON, L. Narcissistic narrative: the metafictional paradox. 2 ed. New York: Methuen, 1984.

LISPECTOR, Clarice. A hora da estrela. Rio de Janeiro: Rocco, 1998.

NAVAS, Diana. Narcisismo discursivo e metaficção em Lobo Antunes: uma leitura de Não entres tão depressa nessa noite escura. 2007. 117 f. Dissertação (Mestrado em Literatura) - Pontifícia Universidade Católica de São Paulo, São Paulo, 2007.

NOLASCO, E. C. Restos de ficção: a criação biográfico literário de Clarice Lispector. São Paulo: Annablume, 2004.

REICHMANN, B. T. O que é metaficção? Narrativa narcisista: o paradoxo metaficcional, de Linda Hutcheon. Scripta Uniandrade, Curitiba, n. 04, p. 333-47, 2006,

VERNECK, Paulo. Estrela Oculta. Folha de São Paulo, São Paulo, 16 dez. 2017.

Recebido em: 29/09/2020.

Aprovado em: 24/11/2020. 